\title{
ADAPTAÇÕES ESPACIAIS E O IMPACTO NO CONFORTO DO USUẢRIO EM HABITAÇÕES DE INTERESSE SOCIAL
}

\author{
SIMÕES, Gianna Monteiro Farias (1); \\ LEDER, Solange Maria (2)
}

(1) UFPB, Mestranda pelo Programa de Pós Graduação em Arquitetura e Urbanismo

e-mail:gianna farias@hotmail.com

(2) UFPB, PhD, Docente e Vice Coordenadora do Programa de Pós Graduação em

Arquitetura e Urbanismo

e-mail:solangeleder@ct.ufpb.br

\begin{abstract}
RESUMO
A habitação de interesse social se caracteriza pela adoção de um projeto padrão de unidade habitacional repetido diversas vezes. Uma das consequências é que grande parte dos usuários para conciliar a unidade às suas necessidades espaciais promovem inserções e reformas já no primeiro ano de uso. Assim, esse trabalho apresenta os resultados de um levantamento realizado em dois conjuntos habitacionais localizados em João Pessoa/PB - amostra de 99 unidades/usuários. Os principais resultados foram que as reformas são realizadas sem apoio técnico e grande parte delas comprometem o conforto e a salubridade dos ambientes, com tendência de ocupação total do lote.
\end{abstract}

Palavras chave: habitação de interesse social; avaliação de desempenho; conforto térmico; reformas.

\begin{abstract}
Housing of social interest is characterized by the adoption of a standard project of housing unit repeated several times. One of the consequences is that most users to reconcile the unit to their space needs promote insertions and reforms in the first year of use. Thus, this paper presents the results of a survey conducted in two housing complexes located in João Pessoa/PB - a sample of 99 units/users. The main results were that the reforms are carried out without technical support and most of them compromise the comfort and salubrity of the environments, with tendency of total occupation of the lot.
\end{abstract}

Keywords: housing of social interest; performance evaluation; thermal comfort; reforms. 


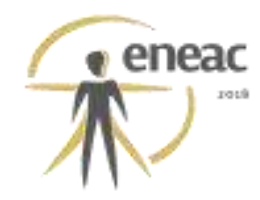

\section{INTRODUÇÃO}

A replicação de um mesmo projeto, tipo arquitetônico único ou projeto padrão, nos conjuntos habitacionais populares desconsidera que as famílias beneficiadas possuem diferentes configurações, assim, frequentemente as unidades habitacionais não atendem as necessidades espaciais dos usuários (DILIGENTI, 2010; ROMERO; ORNSTEIN, 2003; SILVA E., 2011, IMAI, 2013). Em uma unidade habitacional de interesse social (HIS) padronizada que não atende aos diversos perfis familiares e, consequentemente, as necessidades dos residentes, o usuário é "forçado" a se adaptar à moradia, essas adaptações podem ser temporárias ou definitivas, através de alterações físicas ou espaciais.

São diversos os estudos realizados no campo da habitação, alguns voltados na avaliação de desempenho, sendo constatado por vários autores que os conjuntos habitacionais sofrem grande transformação ao longo do uso (SZUCS, 2013; FISCHER, 2003, IMAI, 2013, entre outros), com verdadeiras reformulações espaciais (SZUCS, 1998) motivadas principalmente pela necessidade de aumentar a área da unidade residencial (MARROQUIM, 2007).

A partir de estudos realizados em conjuntos habitacionais de interesse social recentemente implantados, verifica-se a grande incidência de intervenções sem planejamento ou orientação técnica, com desrespeito às regras edilícias (código de obras, etc); a invasão de recuos, afastamentos e até de áreas públicas (FARIAS, 2015). O resultado dessas intervenções, invariavelmente, é o comprometimento da possibilidade de ventilação natural dos espaços internos, do acesso à radiação solar e iluminação natural, bem como a perda da privacidade das famílias.

A questão central dessa pesquisa é a avaliação do desempenho da atual produção de HIS, considerando como acontecem modificações do ambiente construído, adaptações/ampliações nas residências após serem ocupadas, e como isso reflete na qualidade ambiental no interior da moradia. O objetivo principal é caracterizar os padrões de uso e ocupação na habitação de interesse social, com foco no conforto e na adaptação dos usuários e tem como objeto de estudo dois conjuntos habitacionais: Gadanho (Bairro Treze de Maio) e Timbó (Bairro dos Bancários), ambos localizados em João Pessoa/PB e entregues no ano 2013.

A partir dos resultados deste trabalho, espera-se destacar os principais problemas decorrentes da replicação de um projeto padrão, especialmente considerando a condição de clima quente e úmido. Assim, pretende-se colaborar a melhoria da qualidade dos projetos habitacionais de interesse social.

\section{METODOLOGIA}

No presente estudo, foram utilizados procedimentos de avaliação pós-ocupação como ferramenta de análise do desempenho do ambiente construído nas duas comunidades de estudo: Gadanho (tipo arquitetônico= casa térrea geminada em fita) e Timbó (tipo arquitetônico=casa geminada, térreo +1 pavimento, sendo 4 unidades por bloco) (vide figura 1).

A pesquisa é composta por seis etapas: recorte de estudo, elaboração de questionário, estudo piloto, levantamento de campo, tratamento dos dados, análise dos dados. Para a definição da amostra da pesquisa de campo, a técnica definida foi de amostragem não probabilística por conveniência, ou seja, o máximo conseguido, justificada pela possibilidade de acesso. 


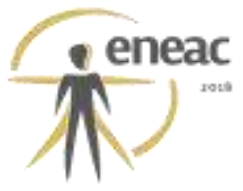

Figura 1 - Comunidades de estudo, Gadanho (à esquerda) e Timbó (à direita).

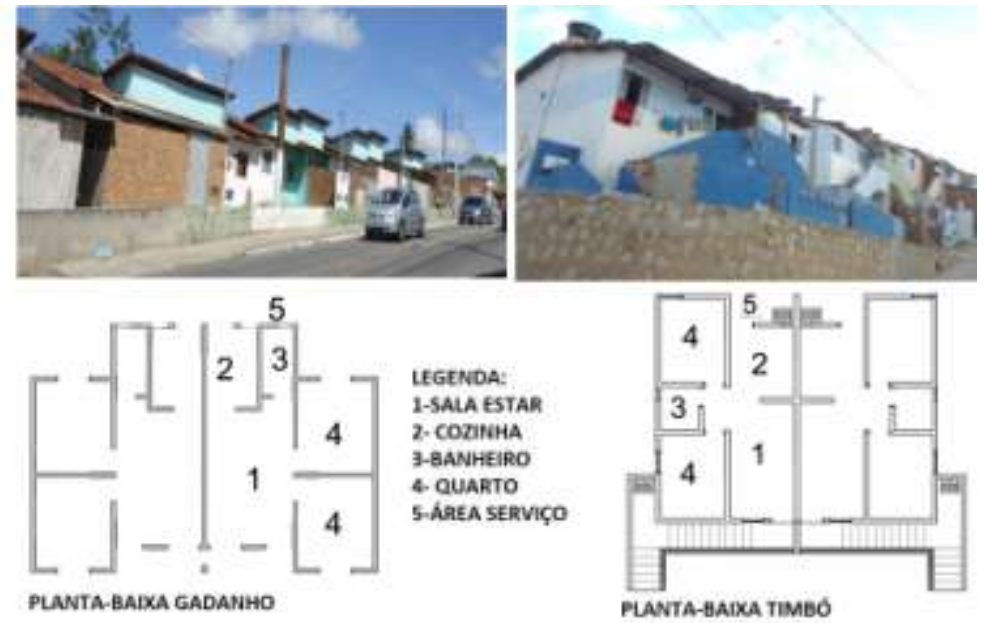

Fonte - Arquivo pessoal, 2017.

A pesquisa experimental apresenta uma abordagem metodológica quanti-qualitativa, cujo método é composto por três grupos de análise: 1 - Adaptação espacial, que representa o estudo das reformas e modificações realizadas na habitação; 2 - Adaptação comportamental, estudo do padrão de uso, que se analisa o comportamento do usuário e a sua percepção sobre o conforto ambiental da moradia e as reformas realizadas; 3 Condições térmicas, que estuda as condições térmicas no interior da moradia. É usado o método da medição de curto prazo (10 minutos - com anemômetro de fio quente e Hobo) na sala de estar das unidades estudadas; a escolha deste ambiente é justificada por ser o local de maior permanência das famílias (FARIAS, 2015).

Especificamente, considerando que a pesquisa está em andamento, neste artigo será abordada a adaptação espacial e parte da adaptação comportamental (conforto do usuário).

\section{RESULTADOS}

Foi coletado um número suficiente para adquirir uma amostra representativa, 99 casas levantadas - sendo $33 \mathrm{UH}$ em Gadanho e 66 no Timbó, o que representa, na primeira comunidade, $73,33 \%$ da população (45 unidades totais), e, na segunda, 48,52\% (136 unidades totais). A população entrevistada em ambos os conjuntos habitacionais é formada, principalmente, por mulheres com idade entre 31 a 40 anos com ensino fundamental incompleto, autônomas ou desempregadas; nas moradias o número de ocupantes varia de 3 a 4 moradores, que estão residindo desde a entrega das construções.

Os resultados obtidos com este trabalho foram divididos em duas etapas: Adaptação espacial e adaptação comportamental, apresentadas a seguir.

\subsection{ADAPTAÇÃO ESPACIAL}

Compreende a adaptação física (reforma) realizada pelo usuário na moradia. O nível de alteração da unidade habitacional é categorizado em três tipos: 1 , casa original; 2 , apenas alteração de abertura (externa - nível da fachada) e/ou inserção de piso cerâmico e, por fim, 3 , casa com ampliação (pode apresentar também o nível 2). No gráfico abaixo, percebe-se como a HIS modifica bastante suas características no pós-uso. $\mathrm{Na}$ amostra, a predominância do nível 3 acontece nas duas comunidades (G: $n=28,84,84 \%$; $T$ : $n=52$, 


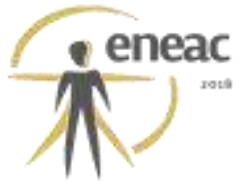

$78,78 \%$ ); também é muito baixo o número de casas que ainda prevalecem com as características originais $(T, n=6,9,09 \%)$; não havendo nenhuma inalterada em Gadanho (vide figura 2). Esses resultados mostram como as casas estão em constante modificação, onde os moradores adaptam à residência aos desejos e às necessidades das famílias.

Figura 2- Nível de alteração da unidade habitacional.

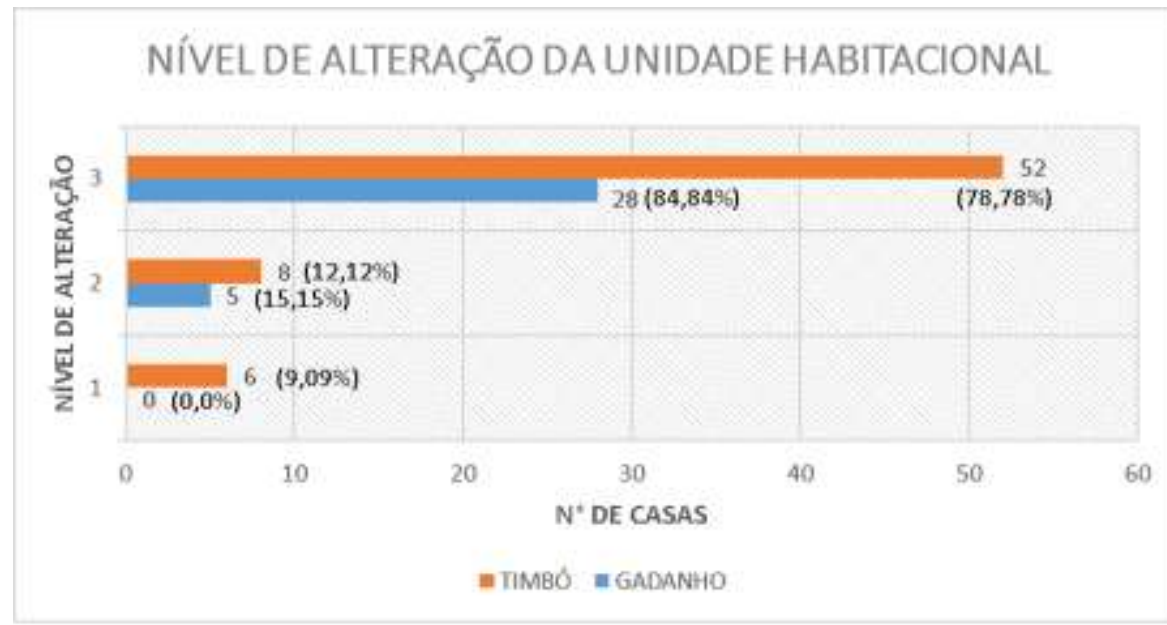

NIVEL DE ALTERAÇÃo:

1 - CASA ORIGINAL;

2 - APENAS ALTERACÅO DE ABERTURA/INSERCX̊O DE PISO CERÅMICO;

3 - AMPLIAÇĀO (PODE APRESENTAR TAMBÉM O NIVEL 2).

Fonte - Dados da pesquisa, elaborado pela autora, 2017.

As opções de reformas encontradas no levantamento de campo foram divididas em categorias, sendo elas: inserção, alteração de aberturas (internas e externas), ampliação.

Ao estabelecer uma discussão sobre os tipos de inserção, são estudados os mais presentes, sendo eles: inserção de muro (G: $n=29,87,87 \%, T: n=51,77,27 \%$ ), piso cerâmico (G: $n=13,39,39 \%, T: n=37,56,06 \%$ ), grade (G: $n=16,48,48 \%, T: n=35,53,03 \%$ ) e forro (G: $\mathrm{n}=3,9,09 \%, \mathrm{~T}: \mathrm{n}=6,9,09 \%)$. O 'muro' é o elemento mais colocado, devido a fatores como: segurança, privacidade, divisão de área com os vizinhos, bloqueio de entrada de animais e perturbação de crianças brincando na rua. No caso do Timbó, também há uma relação entre a apropriação do térreo pelas unidades do pavimento superior, que nem sempre é dialogada de forma amigável, o que gera conflitos após a divisão do lote e até mesmo no uso de esquadrias que passam a ficar na área do vizinho.

A inserção do 'piso cerâmico', vai além da questão estética, pois os moradores relatam a má execução do piso de cimento queimado entregue, que se "esfarela" com pouco tempo de uso e apresenta muitas rachaduras, dessa forma tinham que fazer o investimento com cerâmica, devido a poeira e sujeira dentro de casa. A 'grade' apresenta-se como terceiro elemento mais inserido. O estudo da inserção de grade está associado ao uso, já que os usuários passam a deixar as esquadrias abertas por um período maior de tempo, por se sentirem mais seguros após a instalação do elemento de proteção. Nesse sentido, não poderia deixar de ser mencionada a contribuição da grade para o conforto no interior da unidade residencial, pois alguns moradores relatam que dessa forma podem dormir com as janelas abertas. Por fim, a inserção de 'forro' é elemento menos encontrado em campo. Apesar do relato dos moradores sobre os problemas com a sujeira que vem do telhado e cupim do madeiramento, eles têm receio que a colocação de forro possa deixar a casa ainda mais quente. 


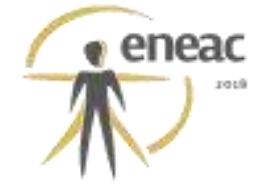

A segunda categoria ilustra a maneira como são realizadas diversas alterações nas aberturas nas duas comunidades da amostra; são elas: inserção de uma esquadria (em outro local/parede do cômodo); troca de esquadria (modificação do material e tipo de abertura, porém no mesmo local da esquadria que foi entregue); retirada de esquadria (fechamento com alvenaria, ou é deixado o vão aberto); e troca do local da porta do banheiro (caso de Gadanho que apresenta o banheiro voltado de frente para a rua). Foi constatado que a maior alteração de abertura em ambas comunidades é a 'troca de esquadria' (G: n=30, 90,90\%; T: n=31, 46,96\%), o que é compreensível, após conhecer os motivos relatados pelos usuários, longe de uma questão apenas estética.

Os motivos para alteração de aberturas são (vide figura 3): 1 - Má qualidade da esquadria entregue, o material de ferro/latão é inadequado para o clima local, o qual enferruja rapidamente, impossibilita o uso e gera perigo de cortes para crianças e adultos, além de barulho e fragilidade para a segurança da casa; 2 - Ampliações da unidade, retirada de esquadria para fechamento de alvenaria ou substituída pela conexão com outro ambiente (vão aberto); 3 - Abertura com cobogó entregue na cozinha e banheiro com área insuficiente; 4 - Conflito com os vizinhos nos recuos laterais (beco), após a divisão dos lotes (caso específico do Timbó); 5 - Janela da sala em conflito no uso, pois a abertura incide na área de circulação dos usuários, causando acidentes (caso específico do Timbó); 6 Localização da porta do banheiro ser voltada para a rua, o que causa perda de privacidade da família e exige cuidados de limpeza constantemente (caso específico de Gadanho).

A 'retirada de esquadria' é a segunda alteração de abertura mais realizada, (G: $n=25$, $75,75 \%$; T: $n=20,30,30 \%)$. Chamam atenção os números de Gadanho, que, apesar de terem a menor amostra, foi a comunidade que mais retirou esquadrias, o que foi justificado, principalmente, pelo número de ampliações realizadas e pela qualidade das esquadrias entregues. Considerando o impacto da retirada de esquadria em relação ao conforto da casa, alguns usuários percebem a diferença após ter sido retirada uma esquadria. Isso reflete a importância das ampliações seguirem orientações, e o tipo arquitetônico possibilitar futuras ampliações, sem comprometer o funcionamento de outros ambientes.

O primeiro quarto ficou mais quente depois que a gente fez esse quartinho, fechou tudo, tirou a janela. (Morador, g2-n2) Ficou um pouco mais quente porque antes podia abrir a porta da cozinha para entrar um ventinho. (g3-s1)

Figura 3- Motivos de retirada de esquadria, 1- ampliações da unidade; 2- fechamento do cobogó, 3- conflito recuo lateral; 4- janela da sala em conflito com uso.

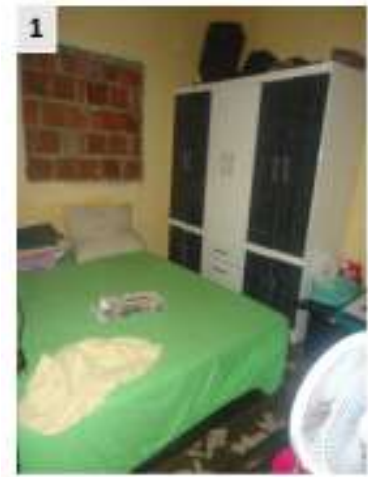

g3-s1

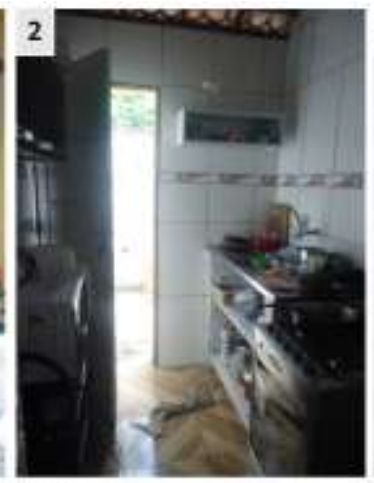

$\mathrm{g} 2-\mathrm{n} 12$

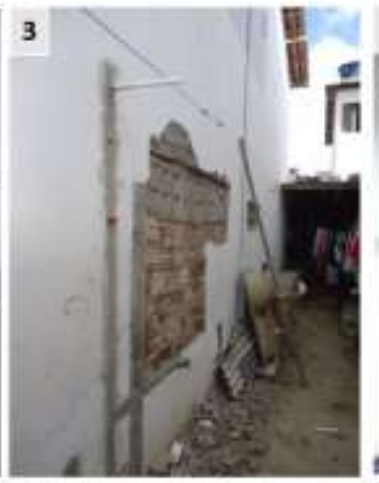

t1-n7-t

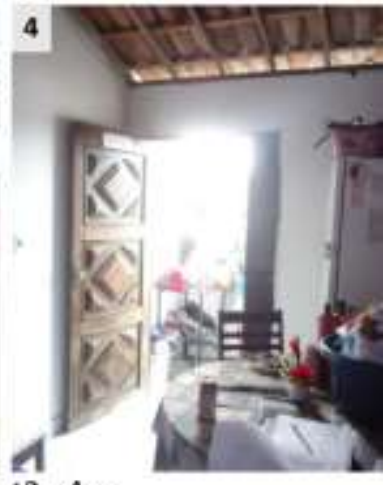

t2-n4-s

Fonte - Arquivo pessoal, 2017. 
Outro nível de detalhamento sobre alteração de abertura é a 'inserção de janela' (G: $n=3$, $9,09 \%, T: n=11,16,66 \%$ ), que acontece principalmente na cozinha e no banheiro, onde não há esquadria, mas sim poucas peças de cobogó. Abaixo seguem alguns trechos de entrevista com usuários, o que mostra como a inserção da janela no local do cobogó é associada aos benefícios na ventilação e iluminação natural da casa.

Coloquei a janela da cozinha, por isso está com uma melhor ventilação. (t1n3-s) A janela da cozinha ajuda muito, fechei aquele negócio (cobogó), queria não. (t1-n3-s) Depois que coloquei as janelas (cozinha e banheiro), não preciso mais ligar a luz de dia. (t1-n1-s)

Por fim, a 'troca do local da porta do banheiro' é uma das alterações realizadas pela comunidade de Gadanho, já que a população não se agrada da porta estar voltada para a rua. Por isso, em 11 casas (33,33\%), foi remanejada a porta do banheiro para abrir pela cozinha, mesmo esse ambiente apresentando medidas reduzidas, o que diminuiria ainda mais devido à inserção da abertura. Em alguns casos, onde não foi possível fazer a alteração devido ao custo que seria necessário, foram encontradas soluções para tentar dar mais privacidade, como uso de cortinas e mobiliário, na tentativa de criar uma barreira visual.

A ampliação é a última categoria de reforma encontrada em campo. Percebe-se que devido ao uso de parcelas estreitas de lotes, restringem-se futuras ampliações, agravado por serem casas geminadas, o que já direciona as expansões e pode favorecer o confinamento da unidade original, como também dos ambientes construídos/ampliados. Constatou-se que um grande número de casas fizeram algum tipo de ampliação, seja ela regular, dentro dos limites do terreno, e algumas de forma irregular, onde há apropriação de área pública (calçadas, áreas livres).

Os tipos de ampliação foram categorizados em: ampliação fechada, semiaberta e aberta (que segue do menor contato da área ampliada com o exterior, ao maior contato).

Ao analisar o número de ampliações por pavimento, observa-se que são muitas as ampliações regulares no térreo em ambas as comunidades ( $G: n=27,81,81 \% ; T: n=45$, $68,18 \%$ ). Entretanto, no Timbó, existe uma peculiaridade, já que a construção no térreo acontece também pelo morador da unidade do pavimento superior, na área obtida após a divisão do lote. Com isso, das 45 unidades do Timbó que fizeram ampliação regular no térreo, 28 pertencem a unidades térreas $(77,8 \%$ das unidades térreas da amostra) e 17 unidades ao pavimento superior (56,7\% das unidades do pavimento superior da amostra). Esse número mostra a necessidade dos moradores do Timbó que residem no pavimento superior em ocupar áreas térreas, já que realizar ampliações no pavimento superior requer investimentos maiores com estrutura (laje estrutural, pilares, vigas). De outra face, o número de ampliações no pavimento superior é expressivo no Timbó devido à grande maioria ser do tipo 'ampliação aberta', ou seja, apenas cobertura, o que representa uma maneira mais simples/fácil de intervenção e não requer tantos investimentos.

O grande número de ampliação regular no térreo do tipo aberta (vide figura 4) justifica-se devido ao beiral original dos dois tipos arquitetônicos apresentar medida reduzida $(0,50 \mathrm{~m})$, assim os moradores passam a complementar áreas de cobertas em trecho ou total. Esse tipo de ampliação também ocorre em áreas de serviço, para proteção da insolação e chuva, pela presença de máquinas de lavar roupa, e também como forma de aumentar áreas sombreadas para a permanência das famílias. 
Figura 4 - Ampliações térreo.

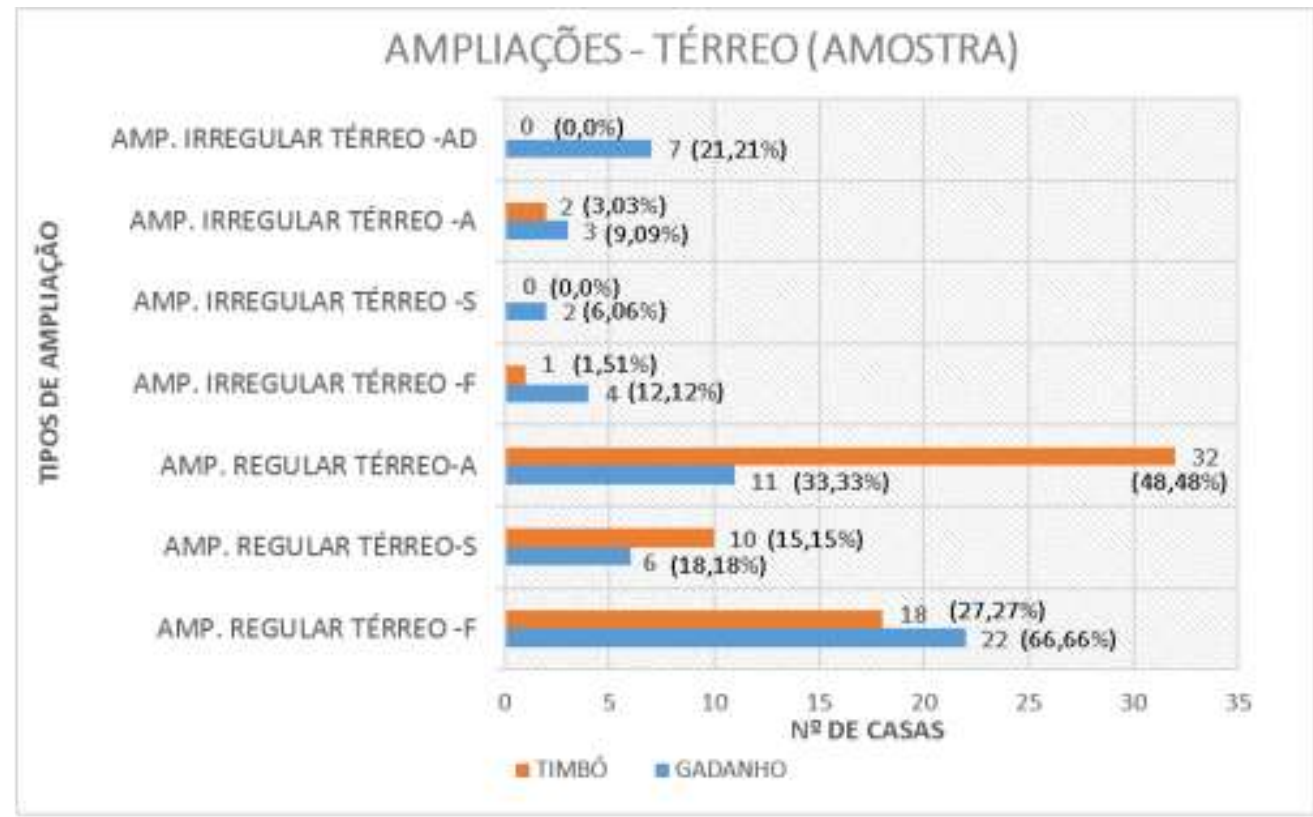

* COMBINAÇ̃̃o = UMA CASA PODE APRESENTAR MAIS DE UMA AMPLIAÇÃONO TÉRREO.

$A M P=A M P L I A C \tilde{O} O ; F=F E C H A D A ; S=S E M I A B E R T A ; A=A B E R T A ; A D=A P R O P R I A C \not ̈ O O ~ D E S C O B E R T A$

Fonte - Dados da pesquisa, elaborado pela autora, 2017.

Além disso, outros itens desse mesmo gráfico mostram o número de ampliações regulares fechadas (vide figura 4), e Gadanho ( $n=22,66,66 \%$ ) apresenta números maiores do que 0 Timbó ( $n=18,27,27 \%)$. Foram analisados os ambientes construídos que representam a maior necessidade das famílias da amostra (vide figura 5), sendo a construção de quarto, área de serviço e ampliação de cozinha os ambientes mais construídos. O problema é que geralmente essas ampliações fechadas ocupam toda a área externa, e quando as ampliações são do tipo fechada, impossibilitam a entrada de vento e luz, piorando às condições térmicas e lumínicas do local, exigindo ainda mais o consumo de energia devido à frequente utilização de ventiladores e de lâmpadas acesas durante o dia. "Depois dessa coberta que fiz na frente, ficou mais quente" (morador, t3-n7-t).

$\mathrm{Na}$ ampliação semiaberta (vide figura 4), o elemento mais construído é o terraço/garagem (G: $n=5,15,15 \%, T: n=9,13,63 \%$ ). A diferença nesse tipo de ampliação é que o fechamento não é completo, ou seja, até a coberta, os usuários deixam a porção superior aberta para ter contato com o exterior, e utilizam grade ou cobogó, como forma de não fechar completamente a área. O último tipo de ampliação é aberta, com construção apenas de cobertura, e ao analisar o térreo das casas da amostra, percebe-se que é realizada, principalmente, para área de serviço ( $\mathrm{G}: \mathrm{n}=5,15,15 \%, T: n=23,34,84 \%)$, pertencentes a unidades térreas e também a unidades do pavimento superior que se apropriam de áreas térreas. 


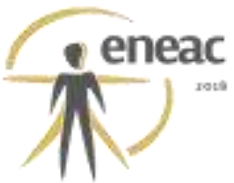

Figura 5 - Ampliação regular térreo fechada.

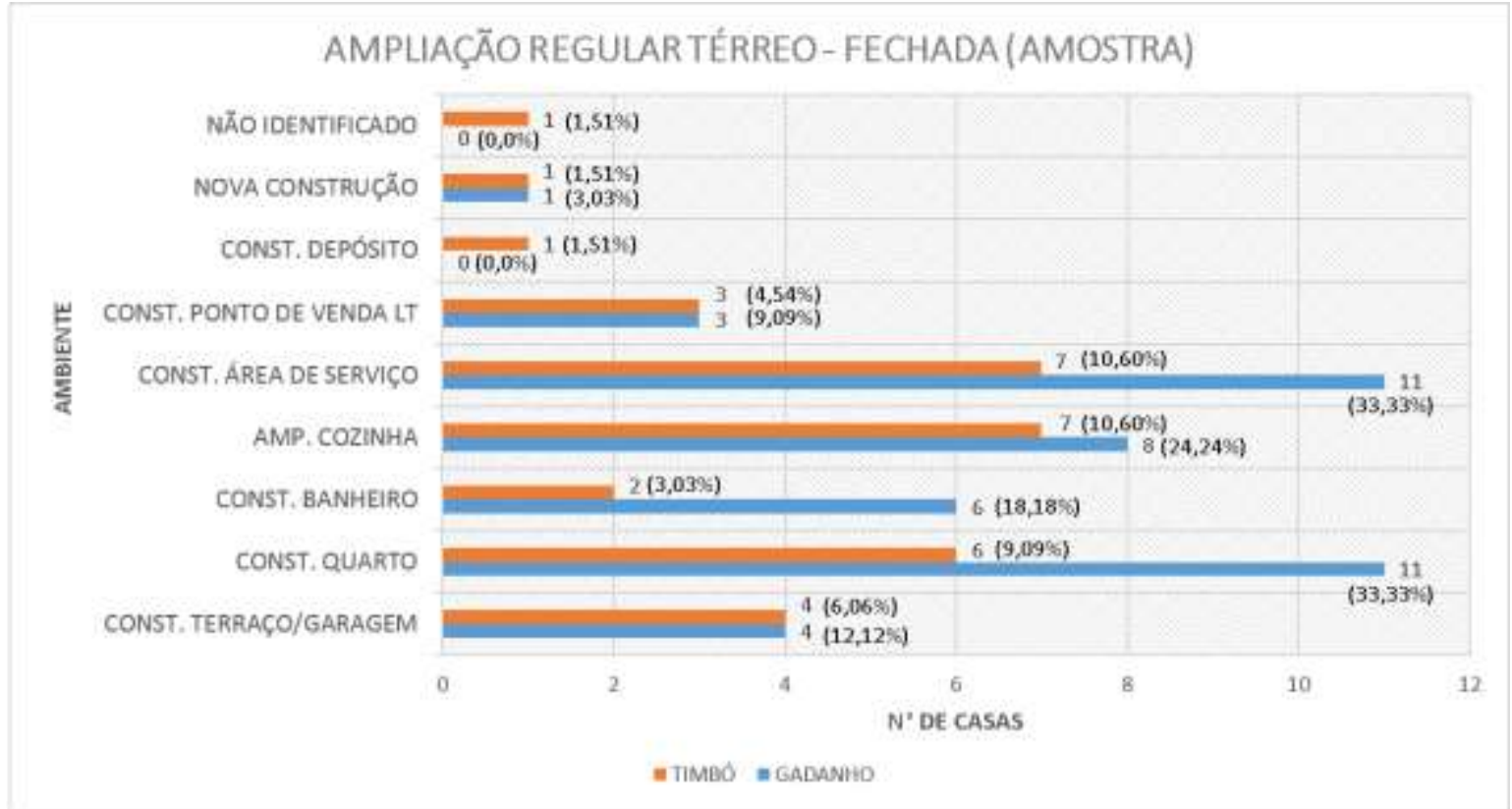

- COMBINAÇÃo = UMA CASA POdE APRESENTAR MAIS DE UM AMBIENTE AMPLIADO NO TÉRREO dE FORMA FECHADA. AMP= AMPLIAC,ÃO; CONST = CONSTRUÇÃO; LT= LOCAL DE TRABALHO.

MATERIAL DE COBERTURA:

(G) $86,36 \%$ TELHA CERÅMICA; 4,55\% TELHA FIBROCIMENTO; 9,09\% MISTO (COMBINAÇÃO DE MATERIAIS);

(T) 33,33\% TELHA CERĂMICA; $27,78 \%$ TELHA FIBROCIMENTO; $11,11 \%$ MISTO; $27,78 \%$ LAJE.

Fonte - Dados da pesquisa, elaborado pela autora, 2017

Em relação à ampliação fechada do pavimento superior, em Gadanho, apenas uma casa da amostra está iniciando a execução (construção da escada) e outra já foi executada (fora da amostra). No Timbó, foram quatro exemplos de ampliação fechada no pavimento superior. Aconteceram dois casos atípicos, onde, em duas casas térreas, realizou-se ampliação no térreo e no pavimento superior. Percebe-se que as ampliações geralmente modificam o tipo arquitetônico; algumas passam a ser verdadeiros paredões, alteram a inclinação e material de coberta e abrem aberturas como podem. Deve-se considerar, entretanto, que a tendência de ampliação das casas do pavimento superior no Timbó acontece de forma aberta (T: $\mathrm{n}=21,70,00 \%$ das casas do pavimento superior), a partir da inserção de complemento de beiral parcial ou total.

Ao se levantar o percentual de cada tipo de ampliação, em Gadanho, foram aproveitadas as possibilidades de expansão de forma coincidentemente equilibrada; $n=12(36,36 \%)$ das casas da amostra expandiram apenas para os fundos, já outros $36,36 \%$ fizeram o aproveitamento frontal e posterior ao mesmo tempo. Deve-se considerar, entretanto, que a localização da cozinha é um importante elemento na direção da expansão, já que é realizada sua ampliação e construção da área de serviço próxima ou compartilhando o mesmo local. No Timbó, foi expressiva a quantidade de casas que fizeram dois tipos de ampliação (frontal e posterior, $n=13,19,69 \%$ ) sendo muitas com fechamento completo frontal, e outras também apenas com trecho na parte posterior da casa.

Conforme levantadas as principais reformas realizadas pelos usuários, foram investigadas, então, as suas motivações. Em Gadanho, o motivo mais representativo é a necessidade de aumentar a área da casa ( $G: n=14,42,42 \%$ ), seguido do aumento no número de ambientes (G: $n=11,33,33 \%$ ); a segurança e melhora dos materiais apresentaram o mesmo percentual (G: n=8, 24,24\%). Já, no Timbó, há a motivação da necessidade de proteger do sol/chuva 
( $T: n=25,37,87 \%)$, seguida da melhoria dos materiais entregues ( $T: n=20,30,30 \%) ; a$ segurança (T: $n=17,25,75 \%)$ e a melhor estética da casa - mais bonita - (T: $n=15,22,72 \%)$.

Apesar de serem encontradas muitas inserções, alteração de aberturas e ampliações nas comunidades de estudo, quase a totalidade dos moradores da amostra relata ainda ser necessário fazer algum tipo de reforma ( $\mathrm{G}: \mathrm{n}=33,100 \%, \mathrm{~T}: \mathrm{n}=64,96,96 \%)$. Destaca-se como principais desejos: trocar portas (G: $n=9,27,27 \%, T: n=25,37,87 \%)$, inserir cerâmica (piso) (G: $n=18,54,54 \%, T: n=20,30,30 \%$ ) e construir laje (G: $n=6,18,18 \%, T: n=17$, 25,75\%).

Percebe-se que as implicações da adoção (replicação) de um único tipo arquitetônico são as adaptações que o usuário tem que recorrer, sejam espaciais, ou seja, reformas na habitação, ou comportamentais, estratégias de uso nos espaços internos para se obter um melhor conforto térmico na moradia.

\subsection{ADAPTAÇÃO COMPORTAMENTAL (CONFORTO DO USUÁRIO)}

Percebe-se que as reformas realizadas na moradia afetam as adaptações comportamentais dos usuários, pois passam a recorrer a diversas estratégias na tentativa de amenizar a sensação de desconforto no interior da moradia. De início é investigada a percepção do usuário sobre o conforto ambiental na casa, e em seguida, as estratégias utilizadas.

Quando questionados a respeito da sensação térmica no local (sala), 19,19\% $(n=19)$ dos usuários consideram o ambiente térmico como confortável (neutro: 'bem, nem com frio nem com calor'), enquanto $79,79 \%(n=79)$ julgaram como desconfortável. A maior razão do desconforto é o calor; $11,11 \%(n=11)$ consideram que estão com 'um pouco de calor'; $18,18 \%(n=18)$ 'com calor' e 49,49\% ( $n=49)$ 'com muito calor'. Em razão do frio, apenas $1,01 \%(n=1)$ julgou estar com um pouco de frio. Ao serem indagados sobre o ambiente térmico que gostariam de estar (preferência térmica, 22,22\% $(n=22)$ dos usuários afirmam que não gostariam de mudanças nas condições térmicas naquele momento, enquanto $70,70 \%(n=70)$ preferem ambiente térmico menos aquecido.

Em suma, os usuários das casas com fachada principal voltada para o norte de Gadanho foram os que apresentaram maior insatisfação com a sensação térmica, maior até mesmo que os moradores do oeste, que afirmam que, apesar da alta insolação na frente da casa, o vento que vem da cozinha (leste) contribui em deixar a casa mais agradável. No Timbó, os ocupantes das casas com fachada principal sul tiveram uma sensação térmica um pouco melhor do que os entrevistados de casas de fachada norte, e também um maior conforto é percebido no pavimento superior, muito mais quando a casa é voltada para o sul, apesar da maioria das casas estar localizada no interior de quadra.

Após conhecer a sensação e a preferência térmica dos usuários, foi questionado, em seguida, sobre o calor em toda a casa. 19 usuários $(19,19 \%)$ informaram que a casa é 'boa', nem quente nem fria, já a grande maioria, ou seja, $70,70 \%(n=70)$ relata desconforto com 0 calor, sendo: $15,15 \%(n=15)$ 'levemente quente', $31,31 \%(n=31)$ 'quente' e $24,24 \%$ 'muito quente'. Apenas dois usuários responderam que a casa é 'fria', a qual está para a melhor ventilação e sem execução de ampliação frontal que contribua como barreira para ventilação.

No que diz respeito ao movimento do ar incidente sobre o usuário na sala de estar, $72,73 \%$ mostram-se insatisfeitos com a velocidade do ar interior e com a pouca distribuição do fluxo de ar dentro dos ambientes. Sobre a preferência em relação à ventilação, como esperado, $68,68 \%$ dos usuários gostariam de uma maior ventilação; nesse caso, a maioria das casas é voltada para o norte. 
Diante do desconforto com o calor relatado pela maioria dos usuários, foi questionado o que eles fazem no dia a dia para se adaptar ao desconforto. São muitas as estratégias (vide figura 6), a principal é o uso do ventilador ( $G: n=27,81,82 \%, T: n=60,90,91 \%)$, com grande percentual para o uso durante todos os turnos $(\mathrm{G}=37,03 \%, \mathrm{~T}=41,66 \%)$. Seguido da necessidade de abrir as esquadrias ao longo do dia para melhorar a ventilação no interior da habitação, e hábitos como tomar bebida gelada e usar poucas roupas (tecido fino, pequeno comprimento). Uma estratégia muito recorrente é a necessidade de sair de casa e ir para rua/calçada (G: $n=20,60,61 \%, T: n=39,59,09 \%$ ) (vide figura 6), a procura é por áreas sombreadas e com melhor ventilação natural, e o retorno à habitação acontece apenas quando diminui o calor no interior (relatado o período noturno). Diante de todas as estratégias relatadas pelos usuários na tentativa de se adaptar ao desconforto, percebe-se o quanto a habitação acaba não favorecendo a permanência dos moradores, sendo necessário muitas vezes recorrer ao exterior.

Figura 6 - Estratégias de uso

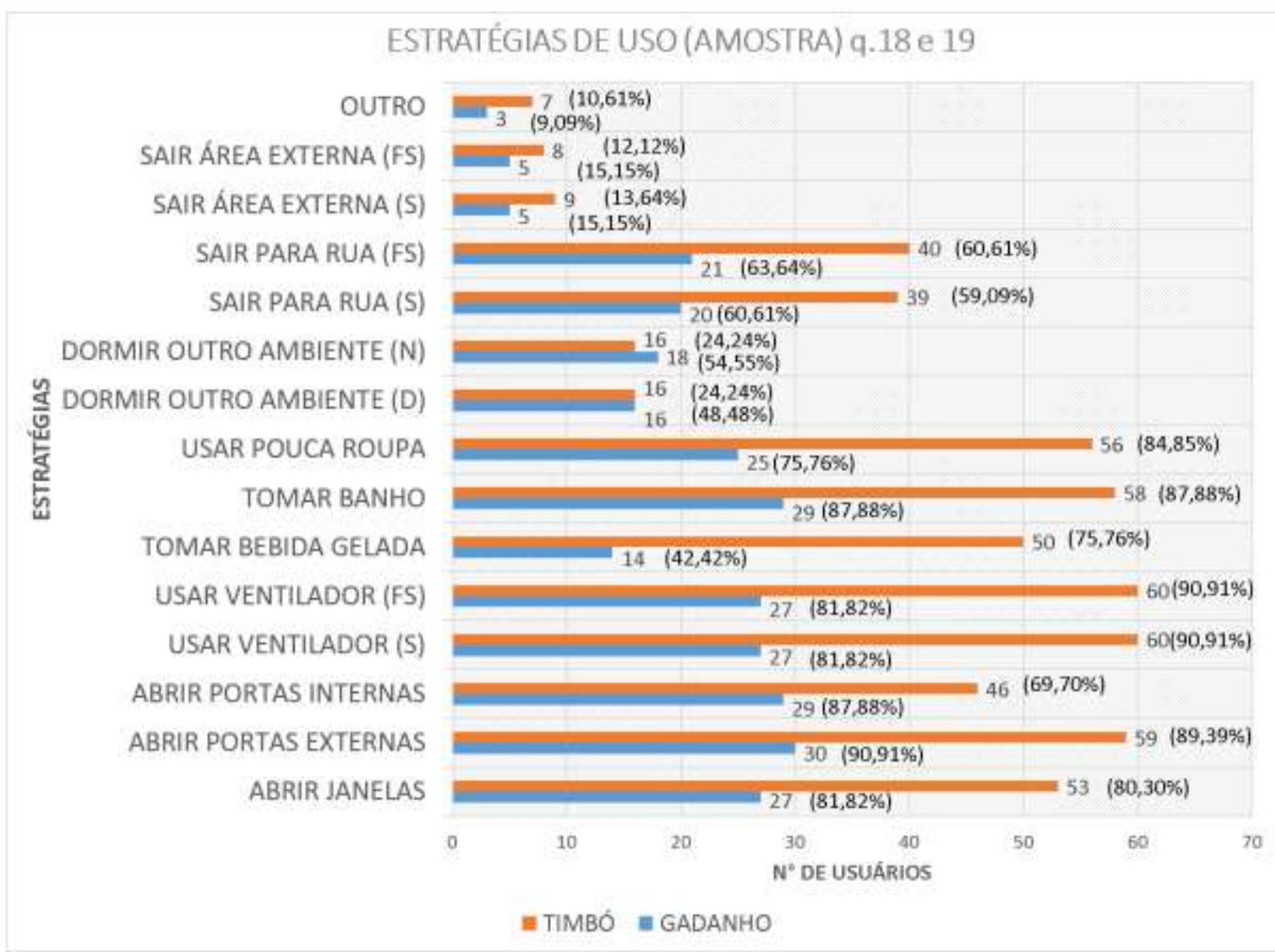

Q18 e19. (QUESTIONÁRIO);

$S=S E M A N A, F S=F I M$ DE SEMANA, $D=D I A, N=N O I T E$

* COMBINAÇÃO = UM USUÁRIO PODE APRESENTAR MAIS DE UMA ESTRATÉGIA, INCLUSIVE MAIS DE UMA OPÇĀO "OUTRO".

"OUTRO" = G * (COLOCAR GELO NO RESERVATÓRIO SUPERIOR PARA TOMAR BANHO (1), DEITAR NO CHĀO FRIO (2);

"OUTRO" $=T^{*}$ (COLOCAR GELO NA FRENTE DO VENTILADOR (1), COMER GELO (1), NĀO SE ENXUGAR APÓS O BANHO (1), DEITAR NO CHĀO FRIO (2), FICAR NO PATAMAR DA ESCADA (1), IR NA PRAIA (1), FICAR SÓ DE CALCINHA (1).

Fonte - Dados da pesquisa, elaborado pela autora, 2017. 


\section{CONCLUSÕES}

Percebe-se que após ocupadas, a dinâmica de reformas e adaptações nas habitações populares é rapidamente iniciada. São algumas as implicações da adoção (replicação) de um único tipo arquitetônico nos conjuntos habitacionais populares: a grande quantidade de adaptações espaciais e comportamentais; comprometimento de parte do orçamento familiar da população de baixa renda para a execução das alterações/reformas necessárias de adequação da casa ao perfil familiar, entre outros. $E$, consequentemente as reformas realizadas implicam diretamente no conforto ambiental no interior da moradia, muitas vezes comprometendo a ventilação e iluminação natural devido aos confinamentos dos ambientes. O cenário de ocupação dessas habitações populares estudadas mostra que há uma tendência em construir fechando toda a área disponível no lote, o que representa inclusive todas as formas de abertura para o exterior, confinando alguns ambientes originais e/ou os novos construídos.

Em campo foram encontradas muitas adaptações, sejam espaciais (reformas) ou comportamentais (estratégias de uso). Sobre as adaptações espaciais, além de inserções e alteração de aberturas, são muitas as ampliações realizadas. A unidade original é modificada devido a necessidade de os moradores terem uma cozinha com dimensão maior e uma área de serviço mais apropriada, com cobertura e espaço para máquina de lavar roupas; terraços para área de permanência prolongada; construção de mais quartos para abrigar famílias maiores, ou tirar filhos do aluguel; áreas para pequeno comércio; complemento de beiral, entre outros.

Foi identificado que as reformas realizadas afetam o conforto do usuários e as adaptações comportamentais, e que os usuários utilizam diversas estratégias no dia a dia para se adaptar ao desconforto no interior da moradia. A sensação de desconforto dos usuários com o calor é da casa como um todo, não é restrito apenas ao ambiente (sala) em que foi realizada a entrevista. Os resultados sobre a preferência corroboram o que foi relatado como sensação térmica, o que evidencia como as habitações das duas comunidades não são confortáveis termicamente para os moradores, pois a maior parcela da amostra se encontra desconfortável com o calor.

Como visto, nem sempre os usuários conseguem, satisfatoriamente, adaptar a residência ao seu conforto. Os moradores buscam minimizar, sobretudo, o desconforto térmico no interior das moradias, recorrendo a estratégias de proteções solares, hábitos e à necessidade de mecanismos artificiais de controle ambiental. Não apenas os custos de reforma são de grande impacto no orçamento familiar, como também o aumento da necessidade de energia elétrica devido ao uso constante de ventiladores e o acionamento de lâmpadas ao longo do dia, agravado com os confinamentos dos ambientes após as reformas realizadas.

Esses resultados levantam a necessidade de repensar esses dois tipos arquitetônicos, com soluções para um melhor aproveitamento das condições favoráveis do local e com previsão da necessidade de expansão da unidade após serem entregues a população beneficiária. Por fim, ressalta-se a importância de haver um melhor planejamento da unidade habitacional, para que as casas não passem a ser espaços confinados após as reformas realizadas pelos usuários, insalubres e que não favorecem permanências. 


\section{(1) $^{\text {enax }}$}

\section{REFERÊNCIAS BIBLIOGRÁFICAS}

DILIGENTI, Marcos Pereira. Sustentabilidade e Habitação de Interesse Social: movimentos sociais e a (re) significação do lugar. In: ENANPARQ - Simpósio Temático: Sustentabilidade na Habitação de Interesse Social: cultural, social, ambiental e econômica, Rio de Janeiro, 2010.

FARIAS, Gianna Guedes Pereira Monteiro. Avaliação pós-ocupação de conjuntos habitacionais de interesse social: Um estudo de caso nos conjuntos Timbó e Gadanho em João Pessoa-PB. Trabalho Final de Graduação - Universidade Federal da Paraíba, João Pessoa, 2015.

FISCHER, Susana. Diretrizes de projeto arquitetônico e design de interiores para permitir a expansão de habitações de interesse social. Dissertação (Mestrado) Programa de Pós-graduação em Construção Civil, Universidade Federal do Paraná, Curitiba, 2003.

IMAI, César. A participação de usuário nos processos avaliativos: metodologias e resultados. In: VILLA, Simone Barbosa; ORNSTEIN, Sheila Walbe (editoras). Qualidade Ambiental na habitação avaliação pós-ocupação. São Paulo, 2013. Cap. 4, p. 75-88.

MARROQUIM, Flávia Maria Guimarães. Avaliação Pós-ocupação de unidades residenciais modificadas de um conjunto habitacional em Maceió - AL: Flexibilidade, Dimensionamento e funcionalidade dos ambientes. Dissertação (Mestrado) Universidade Federal de Alagoas, Maceió, 2007.

ROMERO, Marcelo de Andrade; ORNSTEIN, Sheila Walbe (org). Avaliação pósocupação: métodos e técnicas aplicados à habitação social. Porto Alegre: ANTAC, 2003. (Coletânea Habitare).

SILVA, Elisangela Ferreira. Em busca de habitabilidade: adequações inseridas no conjunto habitacional Boa Sorte em Coimbra - MG. Dissertação (Mestrado) - Programa de Pós-graduação em Engenharia Civil, Universidade Federal de Viçosa, Viçosa, 2011.

SZUCS, Carolina Palermo. Avaliação da qualidade no projeto de HIS: uma parceria com a Cohab/SC. In: VILLA, Simone Barbosa; ORNSTEIN, Sheila Walbe (editoras). Qualidade Ambiental na habitação avaliação pós-ocupação. São Paulo, 2013. Cap. 9, p. 209-233.

SZUCS, Carolina Palermo. Flexibilidade aplicada ao projeto da habitação social. VII Encontro Nacional de Tecnologia do Ambiente Construído Qualidade no Processo Construtivo. Florianópolis, SC, 1998. 